\title{
Heat Conduction in Complex Geometric Structures on Example of Neovius Periodic Surface
}

\author{
R. DyJa* AND E. GaWronska \\ Częstochowa University of Technology, 42-201 Częstochowa, Poland \\ Doi: 10.12693/APhysPolA.139.594 \\ *e-mail: robert.dyja@icis.pcz.pl
}

\begin{abstract}
Heat conduction is an important problem in additive manufacturing, which is the main source of interest for periodic surface structures. The high energy flux, which is required for additive manufacturing to work properly, results in large temperature gradients, which can affect the quality of an obtained part in such properties like porosity or residual stresses. In this paper, we present results of heat conduction calculations in domains of complex geometric shapes expressed by a mathematical description. Such shapes are called periodic surface structures and a well known example of this type of structure is the gyroid, while the Neovius surface is another example. The periodic surface structures can be described by a number of factors, like the thickness or a number of cells, which have impact on their behavior in heat conduction problems. We developed a software that allows for automatic generations of finite element meshes for the Neovius surface according to a given set of parameters. Those meshes are used as an input for heat conduction simulations, whose results are then the base for the analysis of the influence of geometric factors on temperature distribution.
\end{abstract}

topics: FEM, heat transfer, periodic surface structure, numerical simulation

\section{Introduction}

Additive manufacturing is a new technology for the production of elements that was established in the second half of the 20th century. Since it was a new technology, its use was initially limited. In addition to difficulties related to the manufacturing process itself, the lack of the properly adapted design tools and methods also posed a problem. An additional issue was the fact that due to a completely different process of creating an element, element designs - previously considered difficult to make - have now become easy to manufacture [1]. In this situation, structures based on periodic structures have been used. An example of such a structure is the Neovius surface [2]. The use of such structures in the design of elements offers such advantages as reducing the cost of the material used, a direct acceleration of the production time of the element, reduction of the weight of the manufactured element, and thus greater flexibility in the design of elements. It should be emphasized that making elements containing shapes of periodic structures without the use of additive manufacturing would be impossible due to a very complicated shape of such structures [3].

The Neovius surface is an example of a periodic surface with complex geometry. Due to its shape containing smooth rib connections, it requires less material to be produced, while maintaining good technical properties [4]. In addition, a large amount of free space allows easy removal of the powder that remains in the element during additive manufacturing. This makes the Neovius structure an interesting choice for elements produced by additive manufacturing. In recent years, much work has been devoted to investigate similar structures, like the gyroid $[5,6]$.

\section{Geometry description}

An important aspect of the 3D objects description is the choice of their representation. Depending on the purpose, there is, for example, a description with the use of only a surface or a full representation of the volume that facilitate the Boolean operations.

In the case of a surface description, it is possible to come across such forms of description as: explicit, parametric, or implicit. Periodic surfaces are most naturally represented by an implicit formula.

Implicit surfaces are defined as the set of points satisfying the equation:

$$
f(x, y, z)=0,
$$

where $x, y, z$ are the spatial coordinates.

In the case of the Neovius surface [7], named after Finnish mathematician Edvard Rudolf Neovius,

(1) takes the form:

$$
\begin{aligned}
& 3(\cos (x)+\cos (y)+\cos (z)) \\
& \quad+4 \cos (x) \cos (y) \cos (z)=0 .
\end{aligned}
$$


TABLE I

Parameters used for generating different variants of the Neovius structure, together with the value of the Neumann boundary condition.

\begin{tabular}{l|c|c|c|c}
\hline \hline \multicolumn{1}{c|}{ Name } & $\begin{array}{c}\text { Relative } \\
\text { thickness }\end{array}$ & $\begin{array}{c}\text { Volume } \\
{\left[\mathrm{m}^{3}\right]}\end{array}$ & $\begin{array}{c}\text { Side area } \\
{\left[\mathrm{m}^{2}\right]}\end{array}$ & $\begin{array}{c}\text { Heat flux } \\
{\left[\mathrm{W} / \mathrm{m}^{2}\right]}\end{array}$ \\
\hline cube & - & $6.4 \times 10^{-5}$ & $16 \times 10^{-4}$ & 6250 \\
Neovius - 2 cells & 0.1 & $1.113 \times 10^{-5}$ & $2.188 \times 10^{-4}$ & 45694 \\
Neovius - 2 cells & 0.15 & $1.678 \times 10^{-5}$ & $3.578 \times 10^{-4}$ & 27950 \\
Neovius - 2 cells & 0.2 & $2.232 \times 10^{-5}$ & $5.591 \times 10^{-4}$ & 17882 \\
Neovius -4 cells & 0.1 & $1.117 \times 10^{-5}$ & $2.027 \times 10^{-4}$ & 49334 \\
Neovius -4 cells & 0.15 & $1.686 \times 10^{-5}$ & $3.419 \times 10^{-4}$ & 29251 \\
Neovius -4 cells & 0.2 & $2.244 \times 10^{-5}$ & $5.532 \times 10^{-4}$ & 12170
\end{tabular}

In the case of using a periodic surface in additive manufacturing, it is more practical to give (2) a form:

$$
\begin{aligned}
& 3(\cos (x)+\cos (y)+\cos (z)) \\
& +4 \cos (x) \cos (y) \cos (z)=\delta,
\end{aligned}
$$

where $\delta$ specifies the thickness of the structure.

Now, (3) prepared in this way has a convenient form for the preparation of finite element meshes, necessary for numerical calculations. Finite element meshes were generated directly for the given geometry (cube) filled with the Neovius surface with the use of the CGAL library. The CGAL library is often used in places where computational geometry algorithms are necessary, such as computer-aided design, medical imaging, computer graphics, and robotics [6].

\section{Mathematical description of simulating process}

The heat flow model is based on the nonstationary diffusion equation:

$$
\rho c \frac{\partial T}{\partial t}-k \nabla^{2} T=0
$$

where $\rho$ is the density, $c$ is the specific heat capacity, $k$ is the thermal conductivity, $t$ is time, and $T$ is the temperature.

The above result accomplishes the initial condition

$$
T=T_{0}
$$

in the form of a homogeneous temperature field with a prescribed value and also the Neumann boundary condition (type II), i.e.,

$$
-k \nabla T=q
$$

where $q$ is the value of the heat flux density. The Neumann boundary condition, in fact, determines the value of the heat flux flowing through the selected surface.

Now, (4) is solved numerically with the use of the finite element method, where the necessary time integration is performed using the backward Euler scheme.

\section{Problem setup and simulations results}

The presented study deals with a problem of heat conduction in domains of a cube and the Neovius periodic structure. Both the cube and Neovius structure have side length of $0.04 \mathrm{~m}$. Physical properties that were used in simulations are as follows: heat transfer coefficient $k=260 \mathrm{~W} /(\mathrm{mK})$, density $\rho=2800 \mathrm{~kg} / \mathrm{m}^{3}$ and specific heat $c=1000 \mathrm{~J} /(\mathrm{kgK})$. Those physical properties are close to physical properties of aluminum alloys that are often used in the additive manufacturing industry.

A boundary condition of the heat flux was always prescribed on only one side of the region. The exact values of the heat flux are given in Table I, together with other parameters of different geometry cases. The reason for such a variance of the heat flux density was a variable value of the side for different variants of the Neovius structure. This way, it was possible to make sure that in all simulations the amount of energy that flows into the region is the same and equal to $10 \mathrm{~W}$.

All other sides were left without additional boundary conditions, so they were effectively under perfect insulation. The initial temperature for

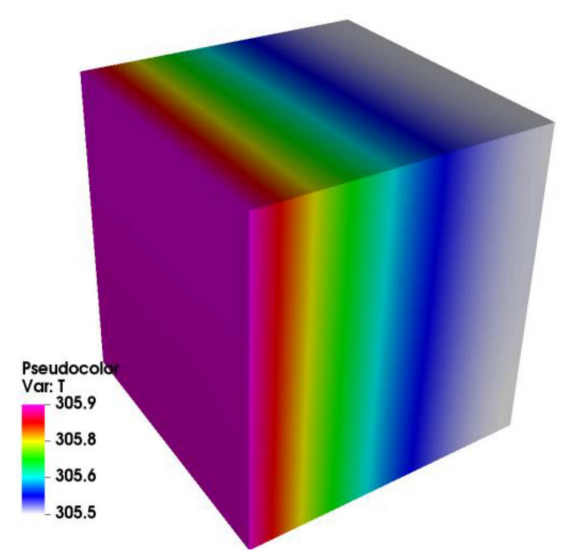

Fig. 1. Temperature field in a full cube after $100 \mathrm{~s}$. 


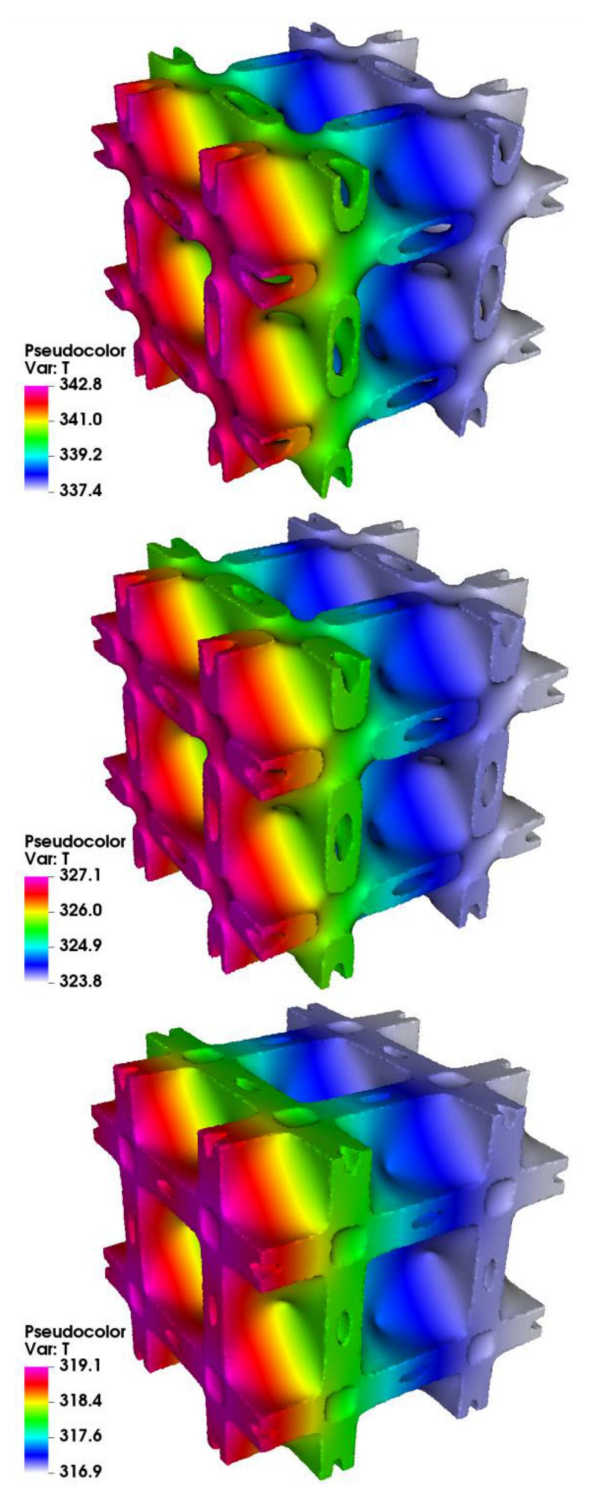

Fig. 2. Temperature field in Neovius structures after $100 \mathrm{~s}$ for the Neovius structure with 2 cells. Relative thickness $\delta$ values are equal to (a) 0.1 , (b) 0.15 , (c) 0.2 .

all cases was $T_{0}=300 \mathrm{~K}$. The presented results are taken in time moment of $t=100 \mathrm{~s}$, when the temperature was not changing rapidly. Achieving a fully steady state was not possible for this set of boundary conditions.

Figures 1-3 show temperature profiles for the cube, the Neovius structure with 2 cells and the Neovius structure with 4 cells, respectively.

The Neovius meshes have much more finite elements than the cube since it was necessary to use ones which are finer to accurately recreate all details of the geometry.

In general temperature profiles in Figs. 2 and 3 resemble temperature profile of the full cube in Fig. 1. Different values of maximum temperature for different cases are mostly due to different values of volume which directly affects heat capacity.

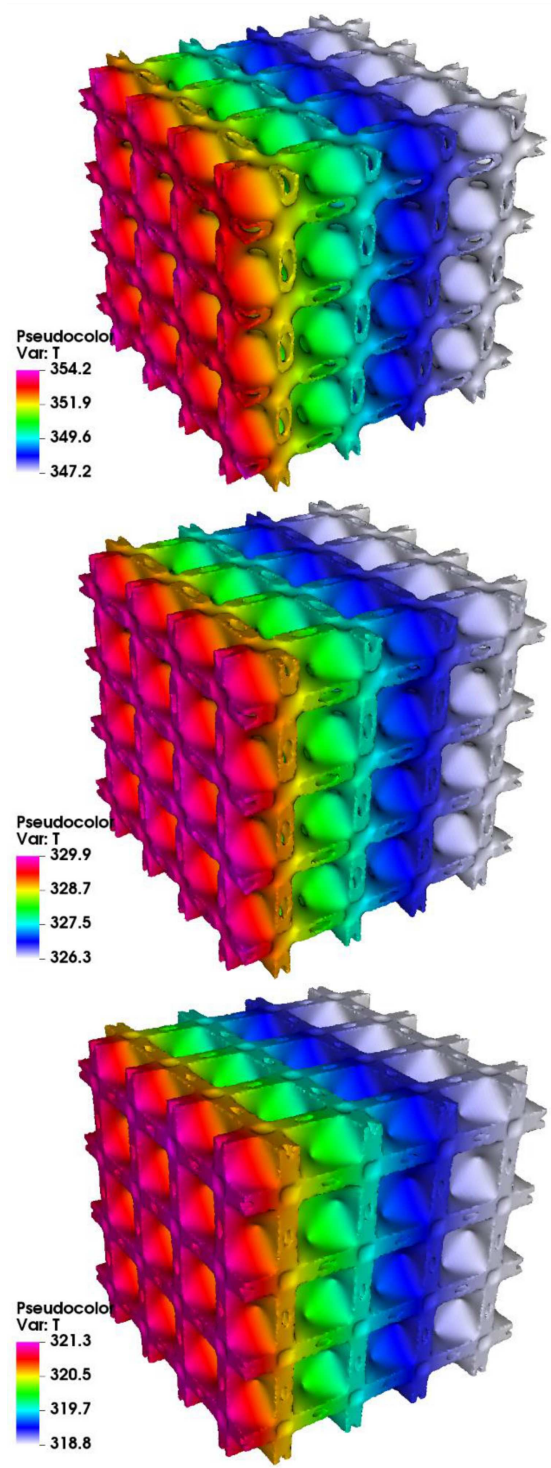

Fig. 3. Temperature field in Neovius structures after $100 \mathrm{~s}$ for the Neovius structure with 4 cells. Relative thickness $\delta$ values are equal to (a) 0.1, (b) 0.15, (c) 0.2 .

It should be noted that Neovius structures with a different number of cells, but with the same value of relative thickness, have a very similar maximum temperature.

\section{Conclusions}

The value of the heat flux density in the Neumann boundary condition was scaled to accommodate for a different single side area of Neovius structures generated with a different set of parameters. In general, structures with lower volume (heat capacity) will heat to higher values of temperature. However, the comparison of results shows that Neovius surfaces with a smaller number of cells heat up to lower values of temperature, even when the volume and side area were comparable. 


\section{References}

[1] C. Yan, L. Hao, A. Hussein, D. Raymont, Int. J. Mach. Tools Manuf. 62, 32 (2012).

[2] E.R. Neovius, Bestimmung zweier specieller periodischer Minimalflächen, aufwelchen unendlich viele gerade Linien und unendlich viele ebene geodätische Linien liegen, J.C. Frenckell \& Sohn, Helsingsfors (Finland) 1883 (in German).

[3] K.V. Wong, A. Hernandez, ISRN Mech. Eng. 2012, 208760 (2012).
[4] C. Beyer, D. Figueroa, J. Manuf. Sci. Eng. 138, 121014 (2016).

[5] E. Gawronska, R. Dyja, Materials 14, 427 (2021).

[6] C. Ya, L. Hao, A. Hussein, P. Young, J. Mech. Behav. Biomed. Mater. 51, 61 (2015).

[7] E.A. Lord, A.L. Mackay, Curr. Sci. 85, 346 (2003). 